\title{
Long-tern Changes in Powdery Mildew (Sphaerotheca macularis) in Strawberry in Eastern China (1985 - 2018)
}

\author{
DH Wang ${ }^{1}$, Y Shen ${ }^{1}$, JD Dai ${ }^{1}$, SF Zhao ${ }^{3}$, and CQ Zhang* \\ ${ }^{1}$ Zhejiang Agricultural Product Quality Supervision, Inspection and Testing Cente, China \\ ${ }^{2}$ Department of Plant Pathology, Zhejiang Agriculture and Forest University, China \\ ${ }^{3}$ Station of Plant Protection of Jiande city, Zhejiang province, China \\ *Corresponding Author: CQ Zhang, Department of Plant Pathology, Zhejiang Agriculture and Forest University, China.
}

Received: August 09, 2019; Published: September 09, 2019

DOI: $10.31080 /$ ASAG.2019.03.0643

\begin{abstract}
The Jiande region is widely known for its high-quality fruit, which are often referred to as "Jiande's strawberries". In this study, the occurrence of powdery mildew on strawberry caused by Sphaerotheca macularis was monitored from 1985 to 2018. In 1985, there were only 1.94 ha of strawberry planted in Jiande, Zhejiang province, which were grown using traditional open field production methods. Since 1993, greenhouse production has been widely adopted and 'Fengxiang' was the dominant cultivars until 2010. Beginning in 2011, 'Fengxiang' was replaced by the 'Hongxia' and 'Zangji' which became the primary cultivars grown. A total of 29 kinds of infective diseases were observed, and anthracnose (Colletotrichum gloeosporioides), grey mold (Botrytis cinerea), and powdery mildew (SPM) (S. macularis) were the most commonly found. The presence of SPM was slight before 1989 when open field cultivation was widespread. During this time, the first serious occurrence appeared during 1995-1999. After 1999, the presence of SPM decreased in most years until 2013. A significant correlation was found between the percent yield loss and SPM, the percent disease index $(Y=$ $0.8774 \mathrm{X}-0.2624, \mathrm{R} 2=0.9624)$, and the percent incidence $(\mathrm{Y}=3.307 \mathrm{X}+0.6513, \mathrm{R} 2=0.8373)$. Our results indicate that the occurrence of SPM is affected by growing conditions, cultivar, and climate, which will provide guidance for the reduction in pathogen pressure in strawberry production.
\end{abstract}

Keywords: Strawberry Production; Disease Monitor; Powdery Mildew; Yield Loss; Disease Occurrence

\section{Introduction}

Strawberry (Fragaria $\times$ ananassa) is a perennial plant in the Rosacea family that was first formally documented in detail 250 years ago. The fruit crop is now one of the most important small fruits globally. China has both the largest area in production $(133,000$ ha) and highest production by weight $(220,000$ tons) of strawberry in a year in the world [1]. Strawberry fruits produced in Zhejiang province are popular, and are of a high quality and yield, with yield outputs greater than 1 billion of CNY (China Yuan) in 2018. Currently, strawberry is one of the leading agricultural industries in the area of Jiande in Zhejiang province, where is famous for "Jiande's Strawberry" for its advanced cultivated and management techniques around China. Strawberry growers from Jiande plant strawberry in 28 of 31 provinces of China, with a total of 5413.3 ha in production and 3.96 billion CNY in sales.

Powdery mildew is an important fungus disease that causes significant damage to many crops worldwide [2]. In strawberry, powdery mildew is caused by Sphaerotheca macularis and causes significant damage, with production loss estimated to be in the range of $20 \%-30 \%$ and as high as $50 \%$ under favorable conditions [3]. The fungal pathogen infects leaves, petioles, runners, flowers, and fruits of strawberry [4], and is known as strawberry powdery mildew (SPM). Symptoms initially occur in the form of white patches on the upper or lower surfaces of young leaves and progress to irregular reddish spots as the disease progresses [5,6]. In China, at present there are no strawberry cultivars that are resistant to SPM and other serious diseases meanwhile with acceptable fruit quality and shelf-life [7-9]. Since 1990 in Zhejiang, strawberry have mostly been planted under un-heated plastic covered tunnels, which will create high-temperature and humidity conditions. Research conducted in Israel suggests that factors such as temperature, relative humidity, and light intensity significantly influence the development of SPM. In this study, we monitored the occurrence of SPM from 1985 to 2018 and compared the resistance to SPM of the main strawberry cultivars.

\section{Materials and Methods \\ Experimental sites}

Three typical strawberry sites in Jiande city, Zhejiang were chosen to monitor the occurrence of SPM. At each site, at minimum of five greenhouses were selected and monitored for the development of SPM at 5-day intervals from November to May. Each greenhouse was divided into five zones containing 10 strawberry plants 
per zone. On each individual plant, the presence of SPM on leaves and fruit was recorded. Fruit yield from plants was also recorded. Prior to 1988, all strawberry plants that were monitored were cultivated in open fields, but greenhouse production was widely adopted thereafter.

\section{Disease scale}

SPM was recorded according to the following scale: $0=$ no symptom; $1=$ diseased area $<5 \% ; 3=5 \%-15 \%$ diseased area; $5=$ 16\%-25\% diseased area; $7=26 \%-50 \%$ diseased area; $9=\geq 51 \%$ diseased area.

The percent of SPM was calculated using the following formula: $\frac{\text { disease number ofleaves or fruits }}{\text { total number of leaves or fruits }} \times 100 \%$ total number of leaves or fruits $\times 100 \%$

The disease index was calculated using the following formula:

$\underline{\sum \text { (number of diseased leaves or fruits of each class } \times \text { each evaluation class) }} \times 100 \%$ total number of leaves or fruits $\times 9$

\section{Damage scale}

Damage due to SPM was calculated as percent of yield loss using the following yield-loss scale: $1=\leq 2 \% ; 2=2.01 \%-5 \% ; 3=5.01 \%$ $8 \% ; 4=8.01 \%-10 \% ; 5=\geq 10.01 \%$.

Yield loss was calculated using the following formula = yield per helaty plant - yield per naturally diseased plant $\times 100 \%$ yield per helaty plant

\section{Results}

Overview of long-term change of strawberry production

In 1985 , only 1.94 ha of strawberry was planted in Jiande in Zhejiang province, and the traditional open field production was most common (Table 1). From 1990 to 1992, the cultural mode transitioned, and by 1993, production under un-heated plastic covered tunnels was most common until 2018 although some glass greenhouses were introduced since 2003.

\begin{tabular}{|c|c|c|c|}
\hline Year & Area (ha) & Cultivar * & Cultural mode \\
\hline 1985 & 1.94 & Shanghai, Geleila, Baojiao, Lihong & Open field \\
\hline 1986 & 2.48 & Geleila, Baojiao, Lihong & Open field \\
\hline 1987 & 3.10 & Geleila, Baojiao, Lihong & Open field \\
\hline 1988 & 3.84 & Geleila Baojiao, Lihong & Open field \\
\hline 1989 & 4.45 & Geleila, Baojiao, Lihong & Open field \\
\hline 1990 & 5.41 & Baojiao, Fengxiang, Mingbao, Meiliu & Open field + un-heated plastic covered tunnels (UPT) \\
\hline 1991 & 7.71 & Baojiao, Fengxiang, Mingbao, Meiliu & Open field + UPT \\
\hline 1992 & 14.04 & Baojiao, Fengxiang, Mingbao, Meiliu & Open field + UPT \\
\hline 1993 & 25.57 & Fengxiang & UPT \\
\hline 1994 & 57.63 & Fengxiang & UPT \\
\hline 1995 & 112.82 & Fengxiang/Chunxiang/Nvfeng & UPT \\
\hline 1996 & 217.40 & Fengxiang, Chunxiang, Nvfeng & UPT \\
\hline 1997 & 694.40 & Fengxiang/Guinvgan/Nvfeng & UPT \\
\hline 1998 & 894.53 & Fengxiang, Guinvgan, Nvfeng, Zangji & UPT \\
\hline 1999 & 885.33 & Fengxiang, Guinvgan, Nvfeng, Zangji & UPT \\
\hline 2000 & 1014.40 & Fengxiang, Nvfeng, Zangji & UPT \\
\hline 2001 & 1021.20 & Fengxiang, Hongxia, Zangji & UPT \\
\hline 2002 & 1060.33 & Fengxiang, Xinxiang, Hongxia, Zangji & UPT \\
\hline 2003 & 1205.80 & Fengxiang, Hongxia, Zangji & UPT+ glass greenhouse \\
\hline 2004 & 1336.00 & Fengxiang, Hongxia, Zangji & UPT+ glass greenhouse \\
\hline 2005 & 1475.47 & Fengxiang, Hongxia, Zangji & UPT+ glass greenhouse \\
\hline 2006 & 1343.33 & Fengxiang, Hongxia, Zangji & UPT+ glass greenhouse \\
\hline 2007 & 1361.93 & Fengxiang, Hongxia, Zangji & UPT+ glass greenhouse \\
\hline 2008 & 1342.33 & Fengxiang, Hongxia, Zangji & UPT+ glass greenhouse \\
\hline 2009 & 1343.87 & Fengxiang, Hongxia, Zangji, Zuohe & UPT+ glass greenhouse \\
\hline 2010 & 1347.53 & Fengxiang, Hongxia, Zangji, Zuohe & UPT+ glass greenhouse \\
\hline 2011 & 1353.73 & Hongxia, Zangji & UPT+ glass greenhouse \\
\hline 2012 & 1368.27 & Hongxia, Zangji & UPT+ glass greenhouse \\
\hline 2013 & 1369.60 & Hongxia, Zangji & UPT+ glass greenhouse \\
\hline 2014 & 1372.67 & Hongxia, Zangji & UPT+ glass greenhouse \\
\hline 2015 & 780.00 & Hongxia Zangji & UPT+ glass greenhouse \\
\hline 2016 & 841.07 & Hongxia, Zangji & UPT+ glass greenhouse \\
\hline 2017 & 937.49 & Hongxia, Zangji & UPT+ glass greenhouse \\
\hline 2018 & 1080.00 & Hongxia, Zangji & UPT+ glass greenhouse \\
\hline
\end{tabular}

Table 1: Strawberry production in Jiande city, Zhejiang province during 1985 and 2018.

*Cultivar were listed from largest area in production to smallest area in production. 
The cultivar Fengxiang was dominant until 2010, and was a cultivar that was adopted for a long time. The largest production area occurred in 2005 and was 1476 ha. From 2004 and 2015, the production area ranged from 1336 to 1476 ha. After 2011, Fengxiang was replaced by Hongxia and Zangji which became the most commonly grown cultivars.

\section{SPM epidemiology trends during 1985 and 2018}

From 1985 to 2018, a total 29 infective diseases were observed on strawberry in our experimental sites (Table 2). Anthracnose, grey mold, and powdery mildew were the most commonly recorded and were observed to be widely distributed and cause measurable damage. The disease incidence of SPM was greatest on leaves slightly before 1989 , when open field cultivation was widespread at the monitoring sites. From 1990 to 1995, the disease index slowly increased, with the first serious outbreak occurring from 1995 to 1999. After this period, SPM on leaves decreased in most years until 2013. From 2014 to 2018, SPM on leaves has been at a high level (Figure 1). A similar pattern was observed for the disease index of SPM on fruits from 1985 through 2017 (Figure 2).

\begin{tabular}{|c|c|c|c|}
\hline Diseases & Distribution regions & Damaged plant parts & Damage degree \\
\hline Anthracnose & City-wide & Leaf, stolon & +++ \\
\hline Grey mold & City-wide & Leaf, flower, stolon, fruit & +++ \\
\hline Powdery mildew & City-wide & Leaf, fruit & +++ \\
\hline Fusarium wilt & Local & Systematic & + \\
\hline Verticillium wilt & Local & Systematic & + \\
\hline Leaf blight & Local & Leaf & + \\
\hline Southern blight & Local & Crown & + \\
\hline Phomopsis leaf blight & Small & Leaf, petiole & + \\
\hline White leaf spot & Small & Leaf & + \\
\hline Angular leaf spot & Small & Leaf & + \\
\hline Black spot & Local & Leaf, fruit & + \\
\hline Brown spot & Local & Leaf & + \\
\hline V-type brown spot & Small & Leaf & + \\
\hline Sclerotinia rot & Local & Root & + \\
\hline Root rot & Local & Root & + \\
\hline Red stele root rot & Local & Root & + \\
\hline Bud blight & Local & Stolon, leaf & + \\
\hline Myxomycosis & Local & Leaf, stolon & + \\
\hline Phytopathora fruit rot & Local & Root, fruit & + \\
\hline Rhizoctonia rot & Local & Fruit & + \\
\hline Fruit rot & Local & Fruit & + \\
\hline Bacterial wilt & Small & Systematic & + \\
\hline Bacterial leaf blight & Small & Leaf, stolon & + \\
\hline Mottle virus (SMoV) & Local & Systematic & + \\
\hline Mild yellow edge virus (SMYEV) & Small & Systematic & + \\
\hline Vein banding virus (SVBV) & Small & Systematic & + \\
\hline Crinkle virus (SCrV) & Local & Systematic & + \\
\hline Witches broom virus (SWB) & Local & Systematic & + \\
\hline Root knot nematode & Local & Root & + \\
\hline
\end{tabular}

Table 2: Types of strawberry diseases found in Zhejiang and their estimated damage.

+++ represents serious damage, ++ represents secondary serious damage, + represents mild damage.

\section{Relation between yield loss and SPM}

For SPM occurrence on leaves, we found a relationship between yield loss (\%) and both the disease incidence $(\%)(\mathrm{Y}=0.2989 \mathrm{x}$ $0.0188, \mathrm{R} 2=0.6288)$ and disease index $(\%)(\mathrm{Y}=0.5838 \mathrm{x}+0.9622$, $\mathrm{R}^{2}=0.5441$ ) (Fig. $5 \mathrm{~A}$ and B). We also found a strong correlation between yield loss (\%) of fruit and the disease index $(\%)(\mathrm{Y}=0.8774$ $\left.\mathrm{x}-0.2624, \mathrm{R}^{2}=0.9624\right)$ and the incidence $(\%)(\mathrm{Y}=3.307 \mathrm{x}+0.6513$, $\mathrm{R}^{2}=0.8373$ ) (Figure 3C and D).
Resistance to SPM between two main varieties

The cultivars Hongxia and Zangji have been widely cultivated in Zhejiang province, becoming the two most important cultivars since 2011 (Table 1). We compared the occurrence of SPM using the disease index of the two varieties (Figure 4) and found that the occurrence of SPM increased in both cultivars over time. While we did find a significant difference in the disease index of several one year $(2013,2014)$, we did not find any significant difference in mean disease index from 2012 through 2017. Qualitatively, we found that SPM was first observed on fruits of Hongxia in 2014. 


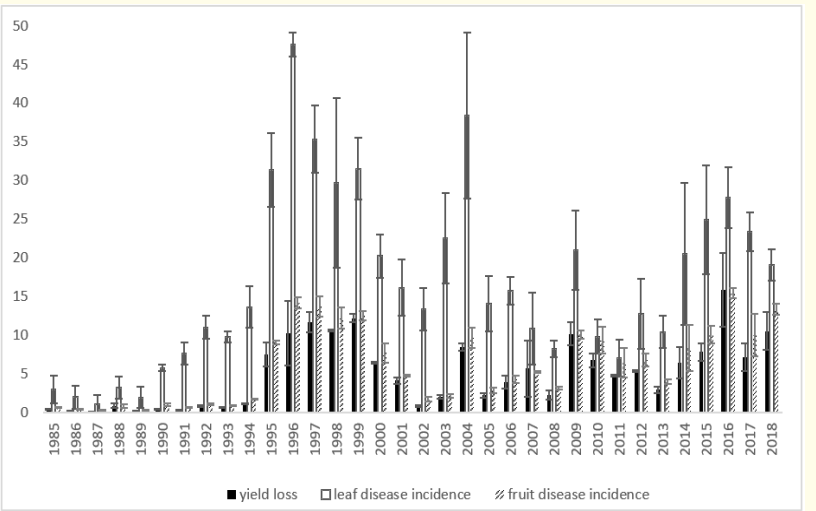

Figure 1: Yield loss (\%) and disease incidence (\%) of powdery mildew on fruits of strawberry during 1985 and 2018 in Jiande, Zhejiang province.

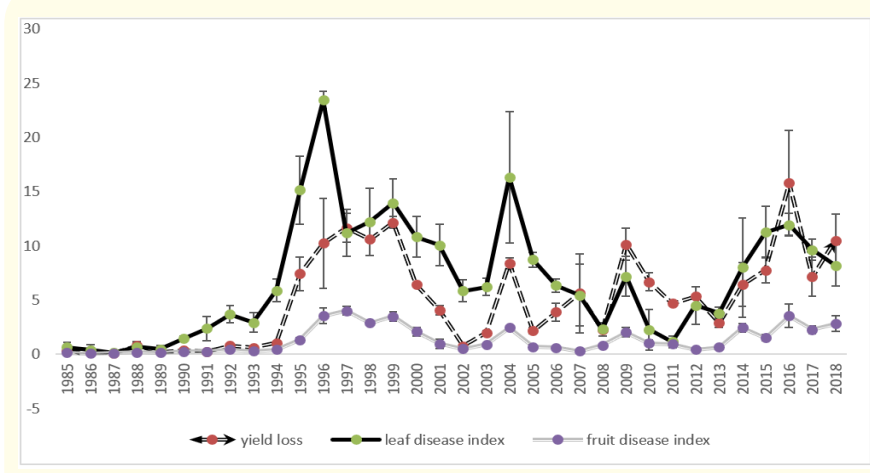

Figure 2: Yield loss (\%) and disease index (\%) of powdery mildew on strawberry during 1985 and 2018 in Jiande, Zhejiang province.

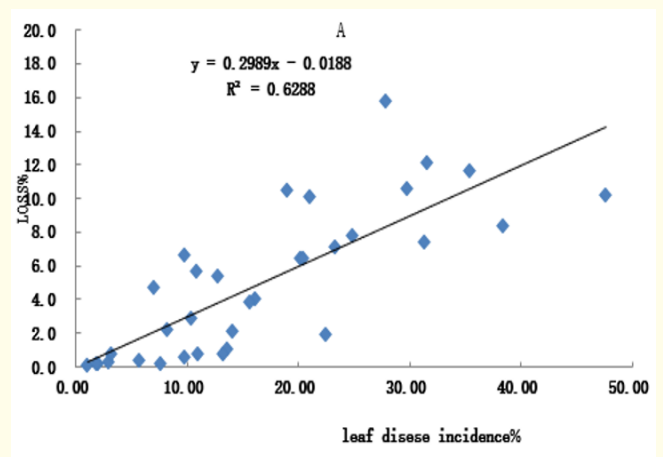

B

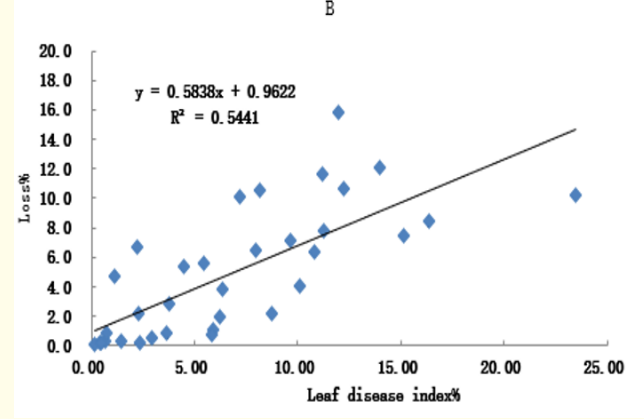

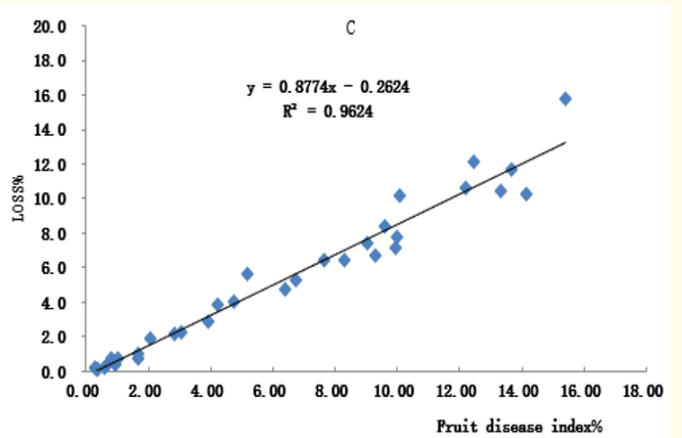

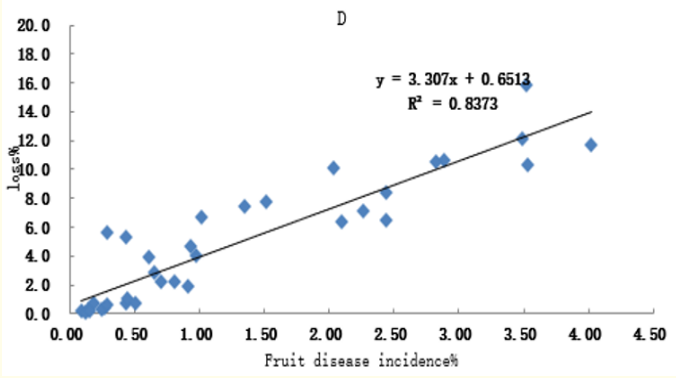

Figure 3: Relationship analysis between yield loss and powdery mildew on strawberry

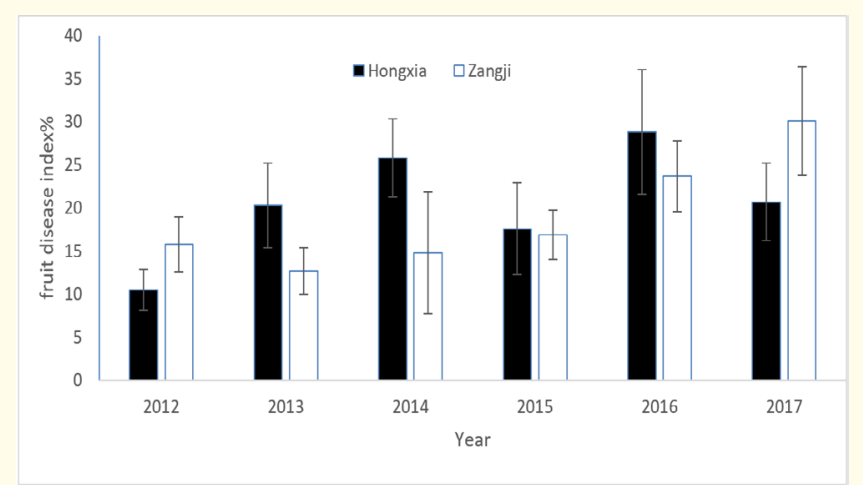

Figure 4: Disease index between Hongxia and Zangji for powdery mildew on strawberry.

\section{Discussion}

From 1985 to 2018, we identified a total of 29 diseases on the strawberry plants we monitored. Anthracnose, grey mold, and powdery mildew were the top 3 important diseases affecting strawberry production due to their wide distribution and serious damage. Anthracnose and grey mold in strawberry have been extensively reported in China [10-13], and over our 34-year study monitoring SPM, we found it to be a serious disease threatening strawberry production in Zhejiang Province, China. We also found that the effect of SPM on yield was statistically significant, and that there was a relationship between the development of SPM and resulting yield loss. Both the incidence and disease index of SPM were linearly correlated with strawberry yield, especially between the disease index of strawberry fruit and yield loss. In hop (Podosphaera macularis), powdery mildew has also been reported to cause serious economic 
loss due to reductions in cone yield and quality [2]. The same effect has also been reported in wine grapes grape, where Uncinula necator has negatively affected yield and quality [14].

Previous studies suggest that temperatures near $20^{\circ} \mathrm{C}$ and a high relative humidity are favorable conditions for the development of SPM [3,4]. In our research, we found that when open field cultivation was adopted, SPM occurred less than in the greenhouse environment. Thus, we believe that the decrease in air circulation, (list other reasons here) in the greenhouse environment created a favorable climate for SPM development. Moreover, the cultivars Hongxia and Zangji have been widely cultivated in Zhejiang province for about 10 years, and we observed an increased trend in the development of SPM. SPM was observed on the fruits of Hongxia in 2017 before being observed on the leaves. In agreement with Nelson., et al. [5,6], we believe that it is important to monitor the long-term changes in resistances of strawberry to SPM [15-17].

\section{Conclusion}

In summary, SPM occurred more in greenhouse production than open beds, and significantly affected the yield of strawberry production in China. Thus, more attention should to be paid to understanding its development.

\section{Acknowledgments}

This work was supported by a grant from the Key Research and Development Project of Zhejiang Province, China (No. 2015C02G1320008). We thank LetPub (www.letPub.com) for its linguistic assistance during the preparation of this manuscript.

\section{Bibliography}

1. Zhao M Z., et al. "Strawberry production and trade in the world and the developmental strategy of strawberry production in Zhejiang". Agricultural Science of Jiangsu 2 (2012): 1-2.

2. Gent D H., et al. "Crop damage caused by powdery mildew on hop and its relationship to late season management". Plant Pathology 63 (2014): 625-639.

3. Miller TC., et al. "Effects of temperature and water vapor pressure on conidial germination and lesion expansion of Sphaerotheca macularis f. sp. Fragariae". Plant Disease 87 (2003): 484-492.

4. Amsalem L., et al. "Effect of climatic factors on powdery mildew caused by Sphaerotheca macularis f. sp. Fragariae on strawberry". European Journal Plant Pathology 114 (2006): 283-292.

5. Nelson MD., et al. "Inheritance of powdery mildew resistance in greenhouse-grown versus field-grown Californian strawberry progenies". Phytopathology 85 (1995): 421-424.
6. Nelson MD., et al. "Relative resistance of 47 strawberry cultivars to powdery mildew in California greenhouse and field environments". Plant Disease 80 (1996): 326-328.

7. Pertot I., et al. "Sensitivity of two Podosphaera aphanis populations to disease control agents". Journal of Plant Pathology 89 (2007): 85-96.

8. Pertot I., et al. "Integrating biocontrol agents in strawberry powdery mildew control strategies in high tunnel growing systems". Crop Protection 27 (2008): 622-631.

9. Sylla J., et al. "In vitro compatibility of microbial agents for simultaneous application to control strawberry powdery mildew (Podosphaera aphanis)". Crop Protection 51 (2013): 4047.

10. Han Y C., et al. "Distribution and characteristics of Colletotrichum spp. associated with anthracnose of strawberry in $\mathrm{Hu}-$ bei, China". Plant Disease 100 (2016): 996-1006.

11. Hu X R., et al. "Rapid on-site evaluation of the development of resistance to quinone outside inhibitors in Botrytis cinereal". Scientific Reports 7 (2017): 13861.

12. Lin T., et al. "Differentiation in development of benzimidazole resistance in Colletotrichum gloeosporioides complex populations from strawberry and grape hosts". Australasian Plant Pathology 45 (2016): 241-249.

13. Zhang C Q., et al. "Sensitivity of Botrytis cinerea to boscalid". Plant Pathology 56 (2007): 646-653.

14. Calonnec A., et al. "Effects of Uncinula necator on the yield and quality of grapes (Vitis vinifera) and wine". Plant Pathology 53 (2004): 434-445.

15. Sun C X., et al. "Degradation of three fungicides following application on strawberry and a risk assessment of their toxicity under greenhouse conditions". Environmental Monitoring and Assessment 187 (2015): 303.

16. Wang G L. "Studies on over-summering and primary infectious pathogen of strawberry powdery mildew in greenhouses in east Zhejiang". Plant Protection 30.1 (2004): 36-39.

17. Xiao C L., et al. "Comparison of epidemics of Botrytis fruit rot and powdery mildew of strawberry in large plastic tunnel and field production systems". Plant Disease 85 (2001): 901-909.

\author{
Volume 3 Issue 10 October 2019 \\ (C) All rights are reserved by CQ Zhang., et al.
}

